\title{
Nanoscale to Macroscale Characterization of in-Situ Bacterial Biopolymers for Applications in Soil Stabilization
}

\author{
Asha Latha Ramachandran, Abhijit Mukherjee and Navdeep K Dhami* \\ School of Civil and Mechanical Engineering, Curtin University, Perth, WA, Australia
}

Bacterial biopolymers produced extracellularly due to microbial metabolic activities have gained considerable interest in various engineering applications. The major advantages of bacterial biopolymers is their in-situ production and low water solubility, eliminating the requirement for mixing in granular substrates such as soils. These properties make them highly desirable and preferable to manufactured biopolymers. But for any engineering applications, it is crucial to understand the mechanical properties of these materials, which have been less explored. This investigation is the first attempt to quantify the nano and macro mechanical properties of in-situ bacterial biopolymer dextran produced by bacterial

OPEN ACCESS

Edited by: Bomou Ma,

Donghua University, China

Reviewed by: Dario Pasini,

University of Pavia, Italy Hao Zhang,

Harbin Institute of Technology, China

*Correspondence:

Navdeep K Dhami

Navdeep.Dhami@curtin.edu.au

Specialty section:

This article was submitted to

Polymeric and Composite Materials,

a section of the journal

Frontiers in Materials

Received: 17 March 2021 Accepted: 22 November 2021 Published: 20 January 2022

Citation:

Ramachandran AL, Mukherjee A and Dhami NK (2022) Nanoscale to Macroscale Characterization of in-Situ Bacterial Biopolymers for Applications in Soil Stabilization.

Front. Mater. 8:681850.

doi: 10.3389/fmats.2021.681850 culture Leucononstoc mesenteroids. The fundamental mechanism of bacterial biopolymer-based cementation has been revealed through their morphographic and nanomechanical testing via atomic force microscopy, nanoindentation and scanning electron micrographs. The effect of bacterially produced biopolymers and commercial biopolymers on the macro-mechanical properties of soils was then investigated via needle penetration tests. In-situ biopolymers were found to be highly effective in stabilizing soils with comparable mechanical properties as commercial biopolymers. This study has demonstrated novel methods for testing in situ polymers and opened up the channels for their applications in numerous subsurface as well as surface applications.

Keywords: biopolymers, bacterial dextran, nanoindentation, AFM, needle penetration

\section{INTRODUCTION}

The role of microbial metabolic activities in the creation of several naturally cementing structures as beach rocks, microbialites, cave speleothems has been widely accepted (Couradeau et al., 2011; Dhami et al., 2018; Ramachandran et al., 2020). In particular, bacterial extracellular biopolymers have been found to significantly influence soil properties in natural systems, as around $10^{12}$ microorganisms per kilogram of soils have been recorded (DeJong et al., 2014). This ability of microbes to create Extracellular polymeric substances (EPS) and biopolymers leading to the cementation of granular materials in natural environments $s$ now being harnessed for several engineering applications, including stabilization of soils, improvement of concrete and immobilization of heavy metals (Dhami et al., 2013; Terzis and Laloui 2019). These bacterially produced biopolymers offer immense benefits, including their eco-friendly nature, recyclability and low water solubility, making them desirable for achieving sustainability goals in the construction industry. 
Commercially available biopolymers and biologically induced polymers offer the advantages of ease of use and sustainability compared to conventional chemical stabilizers (Choi et al., 2020). A range of biopolymers from microbially sources have been utilized for soil stabilization applications, including xanthan, guar gum, gellan gum, chitosan, sodium alginate (Chang et al., 2020; Choi et al., 2020). Commercial biopolymers are first mixed with water creating viscous gels and then supplemented into the soil for applications into soils. Two of the most widely used commercially available biopolymers, xanthan gum and guar gum, have been used extensively in soil stabilization. Their positive impact on soil engineering properties has been recorded in several previous studies (Dehghan et al., 2019; Lee et al., 2019). The properties of the soils improved include strength (Fatehi et al., 2018; Arab et al., 2019), stiffness (Ayeldeen et al., 2017), hydraulic conductivity (Bouazza et al., 2009; Cabalar et al., 2017) and dust resistance (Chen et al., 2015; Chen et al., 2019). Although these commercial biopolymers have several benefits but their high water solubility and high viscosity often limits their ability to penetrate through the soils restricting their usage for several applications.

Emulating the natural process through in-situ production of biopolymers within the soils can overcome the workability issues associated with commercial biopolymers. Stimulation of bacteria present in the soil and subsequent injection of the chemicals required for fermentation can also produce in-situ biopolymers (Kim et al., 2019). This process would obviate the challenges posed by commercial biopolymers with minimum disturbance to the treated soil. Not much information is available on the enrichment and application of native biopolymer producing communities for the creation of in situ polymers, especially for soil applications. A variety of bacterial strains such as Alcaligenes faecalis, Alcaligenes eutrophus and Alcaligenes viscolactis, Microbacterium arborescens (Godinho and Bhosle 2009), Rhizobium tropici (Cole et al., 2012; Ringelberg et al., 2014), Enterobacter aerogenes and Pseudomonas fluorescens (Proto et al., 2016), Bacillus subtilis (Puppi et al., 2016; Cedrati et al., 2020) and Leuconostoc mesenteroids (Ham et al., 2018) have been studied for their ability to produce biopolymers. Amongst these cultures, Leuconostoc mesenteroids (ATCC 14935) has been of keen interest for several engineering applications (Ta et al., 2017). It is a facultative microbe which grows well in both aerobic and anaerobic conditions. Leuconostoc mesenteroids is known to be a non-pathogenic bacteria and does not cause any long term health effects (Jung et al., 2012; Siddiqui et al., 2014). When supplied with sucrose, it can produce insoluble biopolymer dextran (Abbasi et al., 2018). The reactions are as:

$$
\begin{aligned}
& \text { sucrose }+0.2 \mathrm{NH}_{4}++0.341 \mathrm{HCO}_{3}-\rightarrow 0.20 \mathrm{C}_{5} \mathrm{H}_{7} \mathrm{O}_{2} \mathrm{~N}_{(\mathrm{w})} \\
& +0.141 \text { Fructose }+0.071 \text { lactate }+0.071 \text { acetate } \\
& +0.014 \text { Mannitol }+0.071 \text { Ethanol }+0.418 \mathrm{CO}_{2}+0.71 \mathrm{H}_{2} \mathrm{O} \\
& + \text { Dextransucrase }
\end{aligned}
$$$$
5.3 \text { Sucrose + Dextransucrase } \rightarrow 2.0 \text { Dextran }(w)
$$$$
+4.5 \text { Fructose + Dextransucrase }
$$$$
\mathrm{C}_{5} \mathrm{H}_{7} \mathrm{O}_{2} \mathrm{~N}_{(\mathrm{w})} \rightarrow \mathrm{C}_{5} \mathrm{H}_{7} \mathrm{O}_{2} \mathrm{~N}(\mathrm{~s})
$$

$$
\operatorname{Dextran}_{(\mathrm{w})} \rightarrow \operatorname{Dextran}_{(\mathrm{s})}
$$

Dextran is poorly soluble in water, and therefore, it is of prime interest.

However, practical applications require the examination of their suitability as a stabilizer with desired mechanical properties. Very little information is available about the mechanical properties and behaviour of these in situ polymers, especially at the nanoscale. To date, most of the studies have been limited to macroscale tests as strength and stiffness (Cole et al., 2012; Ringelberg et al., 2014), ductility (Ta et al., 2017), hydraulic conductivity (Martin et al., 1996) and cohesion (Ham et al., 2018). A thorough understanding of the biopolymer behaviour at the microscale is crucial before the design and development of its applications at a larger scale.

The engineering properties and durability performance of construction materials at the macroscale are significantly affected by their structural features and properties at the micro and nanoscale where the deterioration and failure process initiates (Zhu et al., 2007; Li et al., 2015). In soils, the nanoindentation technique was exploited in various fields of material characterization, such as determination of elastic modulus and hardness (Oliver and Pharr 1992) and mechanical properties of shale ( $\mathrm{Li}$ et al., 2019). However, the mechanical properties of biopolymer stabilized soils are yet to be quantified using the nanoindentation technique.

The objective of the present study was, therefore, to fill in the gaps of previous research in the characterization of commercial as well as in situ biopolymers at different scales. In order to achieve desired amounts of in situ biopolymers, optimization of media components in order to enhance the production of biopolymer was also carried out. Quantification of nano and micromechanical properties of the biopolymer was conducted. The ultimate objective was to introduce bacterial cells into soils samples in Petri dishes to investigate their effect on surface strength. For this purpose, needlepenetration testing was conducted on the soil samples surface stabilized with in-situ biopolymer. This paper explores the micromechanical and macro mechanical properties of soil stabilized with in-situ deposition of the bacterial polymer. The present study is focused on the advanced nanomechanical characterization of biopolymer dextran leading to application in sand-clay mixtures. Atomic Force Microscopy (AFM) and nanoindentation techniques were used to probe the mechanical properties of the biopolymers at nanoscale and microscale, respectively. Further, penetration tests were carried out in soil samples stabilized with in-situ biopolymer. The mechanism of stabilization has been revealed through advanced microscopic investigations using scanning electron microscopy, nanoindentation and atomic force microscopy.

\section{MATERIALS AND METHODS}

\section{Microorganism and Growth Medium}

The bacterial strain Leuconostoc mesenteroids (ATCC 14935) was selected as a model bacterium for biopolymer production. Leucononstoc mesenteroids is a facultative microbe and grows 
TABLE 1 | Media for the growth of bacteria and biopolymer production.

\section{Media description}

Bacterial growth media

Biopolymer media

\section{Composition}

Leuconostoc mesenteroids (ATCC 14935)

De Man, Rogosa and Sharpe (MRS) broth

Sucrose

Yeast extract

$1 \mathrm{M}$ Monobasic $\mathrm{KH}_{2} \mathrm{PO}_{4}$

$1 \mathrm{M}$ Dibasic $\mathrm{K}_{2} \mathrm{HPO}_{4}$

\section{Concentration}

$0.8<\mathrm{OD}_{600}<1.5$

$52 \mathrm{~g} / \mathrm{L}$

$15-500 \mathrm{~g} / \mathrm{L}$

$10 \mathrm{~g} / \mathrm{L}$

$41 \mathrm{ml} / \mathrm{L}$

$59 \mathrm{ml} / \mathrm{L}$

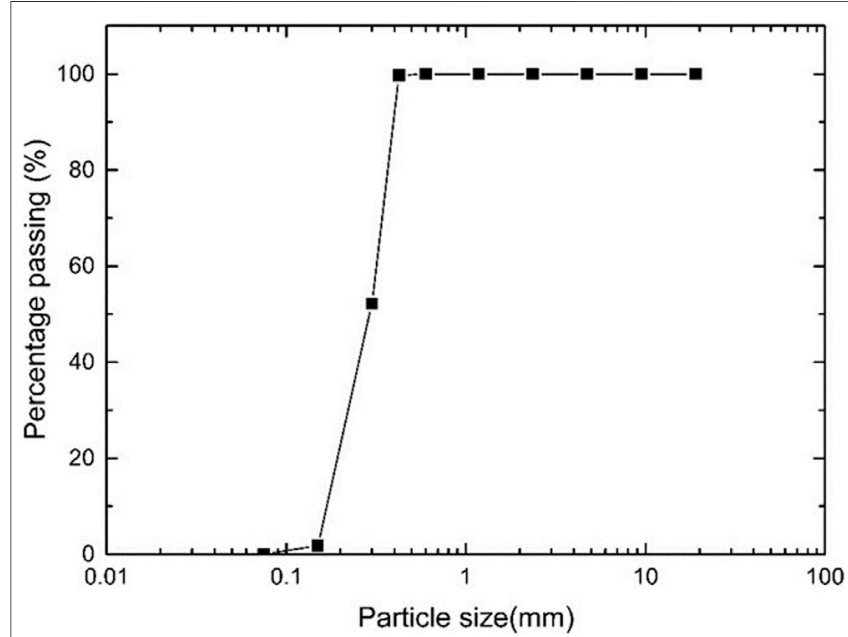

FIGURE 1 | The particle size distribution of the manufactured sand.

in both aerobic and anaerobic conditions. Since Leuconostoc mesenteroids was previously known to plug porous media by producing insoluble biopolymer, it was chosen for the study (Jeong et al., 2019). In addition to this, the bacterial cells have a coccoid morphology with an average diameter of $600 \mathrm{~nm}$, which facilitates microbial transport within the soil matrix. The bacteria produce biopolymer known as dextran while metabolizing sucrose (Noh et al., 2016). Dextran has a branched structure with $\alpha-1$ and $\alpha-2$ glycosidic linkages and is insoluble in water (Noh et al., 2016). Table 1 describes the chemical composition of the growth medium used for growing the bacteria and stimulating Dextran production.

\section{Soil Specimen Preparation}

Manufactured sand with particle sizes varying from 0.45 to $0.075 \mathrm{~mm}$ (Figure 1) used for the present study was sourced from Cook Industrial Minerals, Western Australia. Kaolin clay with low swelling and shrinkage properties supplied by Sibelco, Australia was chosen for the study. The particle size distribution and chemical composition of the clay are listed in Table 2.

\section{EXPERIMENTAL METHODS}

\section{Dextran Production}

Sucrose concentration in the biopolymer media (Table 1) was varied between 15 and $500 \mathrm{~g} / \mathrm{L}$ to study the effect of sucrose

\begin{tabular}{lc}
\hline TABLE 2 | Particle size distribution and chemical composition of the clay. \\
\hline Particle size $(\boldsymbol{\mu m})$ & Percentage passing (\% weight) \\
\hline 53 & 99.4 \\
20 & 97.8 \\
10 & 95.9 \\
5 & 90.3 \\
2 & 75.7 \\
1 & 63.6 \\
$\mathrm{Chemical} \mathrm{analysis}_{\mathrm{SiO}}$ & Composition (\% Weight) \\
$\mathrm{Al}_{2} \mathrm{O}_{3}$ & 46.7 \\
$\mathrm{TiO}_{2}$ & 36.1 \\
$\mathrm{Fe}_{2} \mathrm{O}_{3}$ & 0.8 \\
$\mathrm{CaO}$ & 0.9 \\
$\mathrm{MgO} \mathrm{K}_{2} \mathrm{O}$ & 0.7 \\
$\mathrm{Na}_{2} \mathrm{O}$ & 0.4 \\
& 0.4
\end{tabular}

concentration on Dextran production. For biopolymer production, the bacteria were grown in MRS media until they reached an $\mathrm{OD}_{600}$ of 1 . The bacterial strains were further inoculated in biopolymer media (Table 1) containing varying concentrations of sucrose $(15-500 \mathrm{~g} / \mathrm{L})$. The flasks containing bacteria in biopolymer media was maintained at $37^{\circ} \mathrm{C}$ and $50 \mathrm{rpm}$ for $72 \mathrm{~h}$ to monitor biopolymer production. The $\mathrm{pH}$ was monitored continuously during the process. The contents of the flasks were filtered through Whatman ${ }^{\mathrm{TM}}$ filter paper 1 ( $150 \mathrm{~mm}$ diameter) and dried in the oven at $60^{\circ} \mathrm{C}$ to estimate the weight of biopolymer produced.

\section{Dextran Purification}

Biopolymer extraction was carried out using the modified protocol (Sarwat et al., 2008). To sum up, the media containing bacteria was centrifuged at $6,000 \mathrm{rpm}$ for $20 \mathrm{~min}$ at $4^{\circ} \mathrm{C}$ to remove bacterial cells. The supernatant was precipitated with 2.2 volumes of absolute chilled ethanol by incubating the mixture at $-20^{\circ} \mathrm{C}$ for 1 hour. The precipitated EPS was collected by centrifugation at $6,000 \mathrm{rpm}$ for $20 \mathrm{~min}$ at $4^{\circ} \mathrm{C}$. The supernatant was decanted, and the pellet containing EPS was dried at room temperature in the laminar hood for $6 \mathrm{~h}$. The dry weight of the EPS was estimated.

\section{Scanning Electron Microscopy}

Bacterial biopolymer imaging on glass coverslip substrate was carried out on Tescan Mira3 VP-FESEM with Oxford 
TABLE 3 | Steps involved in polishing for nanoindentation.

\begin{tabular}{|c|c|c|c|}
\hline Polishing & Cloth & Lubricant & Time (min) \\
\hline Step 1 & Piano 220 & Water & 1 \\
\hline Step 2 & Piano 1200 & Water & 2 \\
\hline Step 3 & MD Chem & Colloidal silica (coarseness 0.04 micron) & 2 \\
\hline
\end{tabular}

TABLE 4 | Sample designation for Needle penetration testing.

\begin{tabular}{lcc}
\hline Designation & Biopolymer & Clay (\%) \\
\hline $\mathrm{SB}_{d} \mathrm{CO}^{\mathrm{a}}$ & Dextran (In-situ) & 0 \\
$\mathrm{SB}_{\mathrm{d}} \mathrm{C} 3$ & & 3 \\
$\mathrm{SB}_{\mathrm{d}} \mathrm{C} 5$ & & 5 \\
$\mathrm{SB}_{\mathrm{d}} \mathrm{C} 7$ & & 7 \\
$\mathrm{SB}_{\mathrm{d}} \mathrm{C} 10$ & 10
\end{tabular}

${ }^{a} S$ stands for sand, B for biopolymer and suffix d represents dextran respectively. C stands for clay and its percentage is varied from 0 to 10 .

Instruments X-Max 150 SDD X-ray detector, NordlysNano EBSD detector and AZtec software (Tescan, Czech Republic). The glass coverslips were first rinsed with ethanol followed by deionized water. Further, it is coated with poly-L-lysine $0.01 \%$ (Sigma Aldrich, Australia) and left under a sterile environment for $2 \mathrm{~h}$. Then $20 \mu \mathrm{l}$ of the bacterial grown in sucrose media was added to the coverslips and left overnight. Before the test, $10 \mu \mathrm{l}$ of $4 \%$ glutaraldehyde (Ajax Finechem) was added to fix the cells and left for a period of $10 \mathrm{~min}$. The sample was finally washed with 0.1 M phosphate-buffered saline (PBS) buffer at $\mathrm{pH} 7.2$ and taken for SEM imaging.

\section{Nanoindentation Sample Preparation}

Leuconostoc mesenteroids were cultured in MRS medium (Table 1) until an optical density of one was reached. Further, $1 \%$ of the inoculum was transferred to biopolymer media (Table 1) to induce the production of biopolymer at $37^{\circ}$ for $48 \mathrm{~h}$ at $100 \mathrm{rpm}$. The polymer produced was filtered into Whatman $^{\mathrm{TM}}$ filter paper number one and dried to remove the moisture. The samples were placed in plastic moulds, and epoxy resin (Epofix epoxy) was poured under vacuum (Struers Cito Vac) to impregnate resin into the sample. Stuers Tegramin-30 was used to polish the samples, as mentioned in Table 3. Further, the sample surface was prepared by FIB milling using Technoorg Linda SEMPrep 2 to produce a sample with minimum surface roughness.

\section{Testing Methodology}

Nanoindentation was carried out using a G200 nanoindenter (Agilent Technologies) fitted with a Berkovich shaped diamond tip (TB22130 XP CSM 23032018). The optical microscope attached to the nanoindenter was used at $\times 40$ magnification to choose the points of indentation. The tests were performed under the continuous stiffness measurement (CSM) model with Testworks 4 version 4.10 (MTS System Corporation). While the traditional Oliver-Pharr methodology measures the contact stiffness only at the point of unloading, the CSM technique allows the measurement of contact stiffness at any point of the loading curve corresponding to any depth of penetration. The maximum displacement was limited to $2,000 \mathrm{~nm}$, and 100 indents were chosen on the sample with a spacing of $20 \mu \mathrm{m}$. All the indentation locations were carefully selected prior to testing to ensure that the pores or cavities were not encountered in the process. Poisson's ratio of the biofilm was taken as 0.45 (unpublished study). Software nanoTest Platform Four V.40.08 (Micro Materials Ltd.) was used to compute the Elastic modulus and hardness of the biopolymer sample. To obtain the properties of hydrated biopolymers, the sample cast in resin was immersed in deionized water for $24 \mathrm{~h}$ and allowed to saturate before carrying out the test.

\section{PeakForce QNM}

PeakForce quantitative nanomechanical imaging (PeakForce QNM) was employed to study the nanomechanical properties of biopolymer at high resolution. The instrument facilitated the mapping of elastic properties of the sample with a lateral resolution at the nanometre scale. The force curves were analyzed at each pixel of the topographic image, and the local elastic modulus was calculated at each surface contact with the sample using the Derjaguin-Muller-Toporov (DMT) model (Smolyakov et al., 2016). The forces during tip-surface interaction can be described elsewhere (Smolyakov et al., 2016). The above calculations were carried in real-time for each force-distance curve obtained at every pixel leading to the simultaneous mapping of the nanomechanical properties and topography of the sample. AFM imaging was performed using Bruker Dimension Icon AFM system with PF QNM mode under ambient conditions. SCANASYST-FLUID probes were employed for the experiment (SCANASYST-FLUID with spring constant $0.7 \mathrm{~N} / \mathrm{m}$, Bruker, US). The imaging scan rate was maintained at $1 \mathrm{~Hz}$ at a resolution of $256 \times 256$ pixels. The raw AFM topography images were further processed by using Bruker Nanoscope Analysis 1.9.

\section{Needle Penetration}

Petri dishes ( $85 \mathrm{~mm}$ diameter and $10 \mathrm{~mm}$ height) were filled with $100 \mathrm{~g}$ of soil each and tapped for compaction. The soil was a wellgraded system with sand and varying percentage of kaolin clay $(0$, $3,5,7$, and $10 \%$ ) as in Table 4 . The initial weights of the samples were measured. During the treatment process, MRS media $(10 \mathrm{ml})$ containing Leuconostoc mesenteroids was sprayed on the soil surface under sterile conditions. The samples were transferred to an incubator maintained at $37^{\circ} \mathrm{C}$ to promote the growth of the bacteria. After $6 \mathrm{~h}$, the sample was taken out, and $10 \mathrm{ml}$ of biopolymer media containing sucrose was sprayed on the sample to initiate biopolymer production. Weights of the samples were continuously taken prior to and after each spraying to 


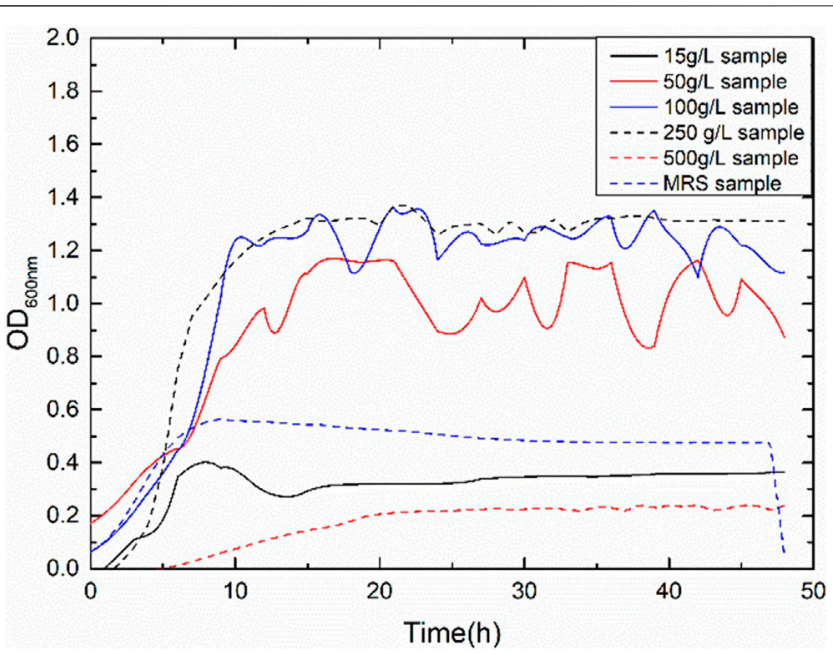

FIGURE 2 | Bacterial growth in media with different sucrose concentrations.

estimate the amount of media absorbed by the sample accurately. After 4 days of spraying the samples with biopolymer media, fresh bacteria were resprayed. The cycle was repeated for 21 days of treatment. The amount of polymer deposited was estimated by chemical mass balancing. While the needle penetration test is not a standardized test, it has been used by researchers in order to achieve an indirect measure of the strength of stabilized soil (Callebaut et al., 1985; Ulusay et al., 2014; Gowthaman et al., 2019). A penetration test set up was developed in house with Chenille 22 needle of diameter $0.94 \mathrm{~mm}$ and length. The needle inserted into a stainless-steel holder, and the set up was clamped to the jaws of universal testing machine (Shimadzu AGS-X). The loading was carried at a rate of $0.5 \mathrm{~mm} / \mathrm{min}$ to a maximum penetration of $5 \mathrm{~mm}$. For each sample, the penetration was carried out at 25 points spaced $10 \mathrm{~mm}$ apart to obtain average Needle Penetration Resistance (NPR) values.

\section{RESULTS AND DISCUSSION}

\section{Bacterial Growth and Biopolymer Production}

Figure 2 presents the growth curves with varying sucrose concentrations. The highest rate of bacterial growth was observed with sucrose concentration of 100 and $250 \mathrm{~g} / \mathrm{L}$ with bacterial $\mathrm{OD}_{600 \mathrm{~nm}}$ greater than one. The lowest growth rate of the bacteria occurred in media with the highest sucrose concentration of $500 \mathrm{~g} / \mathrm{L}$. The ATCC suggested media (MRS media) for the growth of the bacteria displayed an $\mathrm{OD}_{600 \mathrm{~nm}}$ of 0.6. Hence, a sucrose concentration of the media was maintained at $15 \mathrm{~g} / \mathrm{L}$ and $100 \mathrm{~g} / \mathrm{L}$ of sucrose for needle penetration experiments. The initial $\mathrm{pH}$ of the media was adjusted to 7 by the addition of phosphate buffers. With the growth of bacteria, the $\mathrm{pH}$ of the media dropped due to the production of carbon dioxide and other by-products of

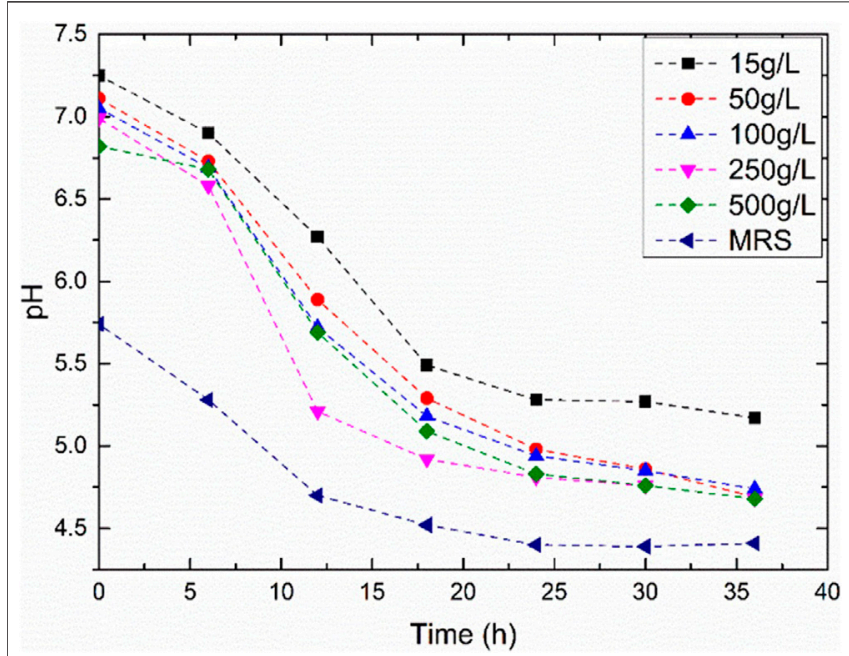

FIGURE 3 | Variation of $\mathrm{pH}$ with sucrose concentration.

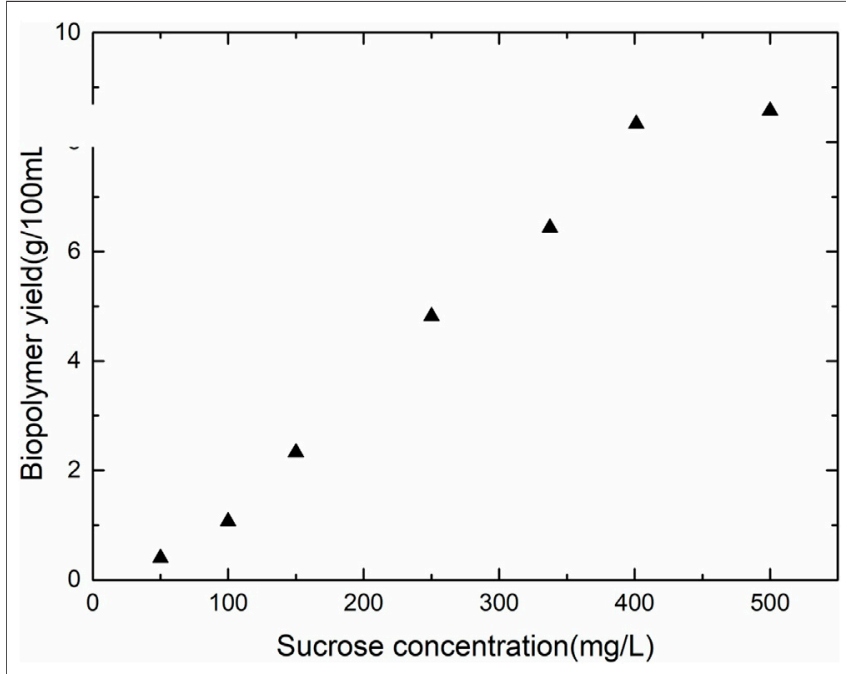

FIGURE 4 | Biopolymer yield with varying sucrose concentration.

the fermentation reaction (Figure 3). The $\mathrm{pH}$ drop is drastic between 5 and $12 \mathrm{~h}$ from the period of inoculation. The value of the $\mathrm{pH}$ attains a stable value after the end of $24 \mathrm{~h}$, indicating the end of the fermentation reaction. Figure 4 shows the weight of biopolymer production with an increase in sucrose concentration in the media from 15 to $500 \mathrm{~g} / \mathrm{L}$. The biopolymer formation increased with an increase in sucrose concentration, as observed from Figure 4. It has been reported that the bacterial activity leading to dextran production can be divided into three stages, namely, bacterial growth, dextran production and dextran precipitation. When Leuconostoc mesenteroids are grown in sucrose rich conditions, the bacteria produce an enzyme known as dextransucrase leading to the precipitation of biopolymer dextran $\left(\mathrm{C}_{6} \mathrm{H}_{10} \mathrm{O}_{5}\right)_{\mathrm{n}}$. The reaction for cell growth and enzyme production are as follows: 

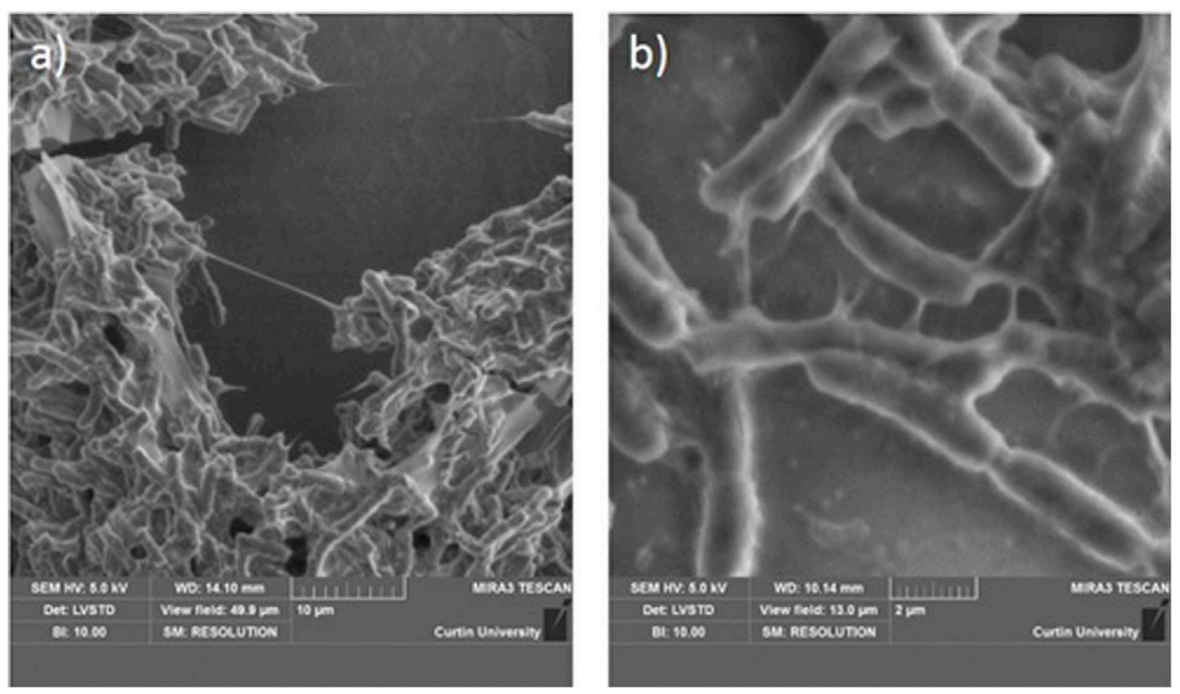

FIGURE $\mathbf{5}$ | (A,B) SEM micrographs of bacterial biopolymer on glass-slides.

$$
\begin{aligned}
& \text { sucrose }+0.2 \mathrm{NH}_{4}++0.341 \mathrm{HCO}_{3}-\rightarrow 0.20 \mathrm{C}_{5} \mathrm{H}_{7} \mathrm{O}_{2} \mathrm{~N}_{(w)} \\
& +0.141 \text { Fructose }+0.071 \text { lactate }+0.071 \text { acetate } \\
& +0.014 \text { Mannitol }+0.071 \text { Ethanol }+0.418 \mathrm{CO}_{2}+0.71 \mathrm{H}_{2} \mathrm{O} \\
& + \text { Dextransucrase }
\end{aligned}
$$

5.3 Sucrose + Dextransucrase $\rightarrow 2.0$ Dextran $(w)$

+ 4.5 Fructose + Dextransucrase (2)

$$
\begin{array}{r}
\mathrm{C}_{5} \mathrm{H}_{7} \mathrm{O}_{2} \mathrm{~N}_{(w)} \rightarrow \mathrm{C}_{5} \mathrm{H}_{7} \mathrm{O}_{2} \mathrm{~N}(s) \\
\operatorname{Dextran}_{(w)} \rightarrow \operatorname{Dextran}_{(s)}
\end{array}
$$

The subscript $\mathrm{w}$ represents biomass species that are present in water but not dissolved in it and the subscript $S$ represents species that are attached to the solid. Where $n$ was assumed to be 6.2 due to the molecular weight of generated dextran being approximately $10,000 \mathrm{~g} \mathrm{~mol}^{-1}$. The dextran produced is said to have very low solubility in water and contribute to permeability reduction.

The preliminary screening was conducted to understand the optimal bacterial and sucrose concentration for biopolymer production. This information is crucial for investigating the suitability and potential of in-situ biopolymers for soil stabilization applications.

\section{Scanning Electron Microscopy}

Figure 5 shows the typical morphology of microbial biopolymers along with the bacterial cells. They are viscous and stretch to thin threads when pulled. The length of a single biopolymer thread is around 10 microns, as seen in Figure 5A. Figure 5B shows several such threads. The micrographs clearly show that bacteria use biopolymers as anchors to attach themselves to a substrate. Thus, the bacteria attach to soil grains, and the threads bridge the grains. The stiffness of the bacterial biopolymers is significantly different in the dry and hydrated states leading to the difference in their mechanical properties as well. When wet, the threads are able to elongate considerably to attach to a number of grains. When the polymer dries, the threads develop cohesive strength among the grains. Microscopic investigations are crucial in understanding how the bacteria attach themselves to the substrate and to visualize the nature of biopolymer production. This information is very crucial to in-situ soil stabilization applications.

\section{Nanoindentation}

Figure 6A shows the biopolymer sample prepared for nanoindentation. It is embedded in a resin and polished using the ion milling technique. Figure 6B shows the indentation marks left on the samples after the indentation test. Nanoindentation was performed by constantly penetrating the indenter into the polymer and measuring the force of resistance. Figure 7A shows a typical variation of the elastic modulus and hardness with the depth of penetration. It is observed that for the initial $250 \mathrm{~nm}$ of penetration, the indenter moves freely, and the force of resistance has a downward trend with penetration. This is possibly due to the surface unevenness of the sample. From 260 to $500 \mathrm{~nm}$, the indenter experiences increased resistance-the force of resistance peaks at around $55 \mathrm{~nm}$ penetration. Thereafter, there is a gradual reduction in resistance. The force of resistance stabilizes at around $1,000 \mathrm{~nm}$. From $1,000 \mathrm{~nm}$ to $2000 \mathrm{~nm}$ depth, there is little change in the force of resistance. Similar observations have been made in (Nix and Gao 1998). The average elastic modulus measured at depths of $1,000-2,000 \mathrm{~nm}$ is considered to be representative. It was observed that the average elastic modulus of the dry biopolymer is $3.14 \mathrm{GPa} \pm 0.035$. The hardness of the biopolymer is derived from the measured elastic modulus. The average hardness is observed to be $0.2 \mathrm{GPa}$.

The elastic modulus of the biopolymer lies within the modulus range of 0.1-5 GPa (Wang et al., 2005; Jee and Lee 2010). The possible reason for such a large variation is the extreme moisture 

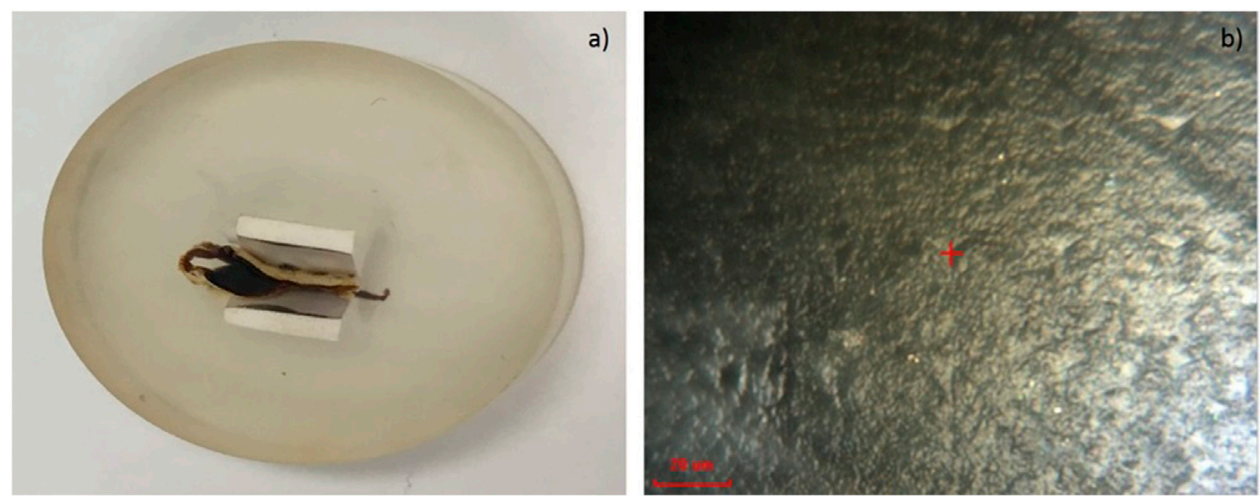

FIGURE 6 | (A) Biopolymer sample embedded in resin for nanoindentation testing (B) image of a typical indent on the sample.

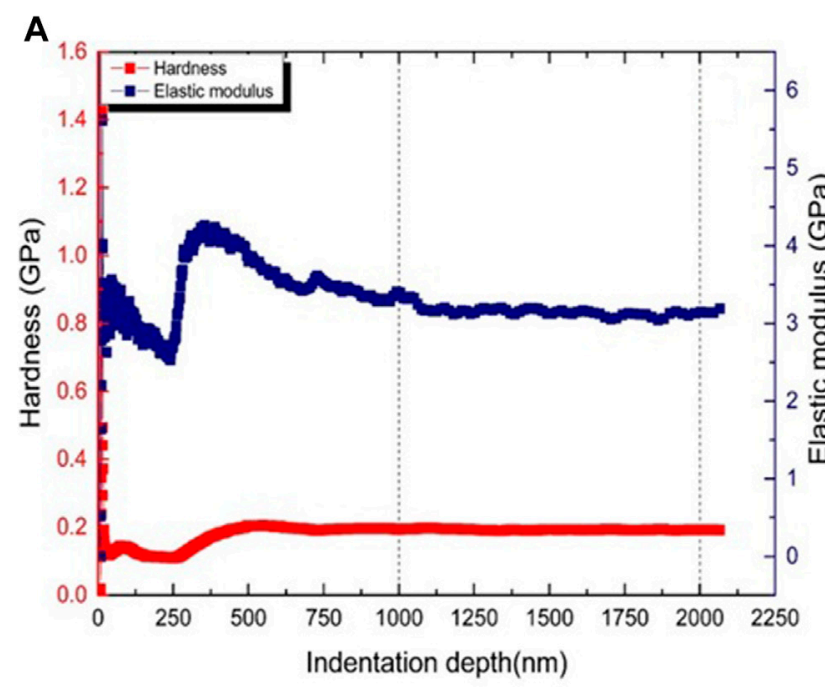

B

FGURE 7 | (A) Elastic modulus and hardness as a function of the penetration depth (B) Variation in modulus of dry and hydrated biopolymer sample.

sensitivity of the biopolymer. The authors have reported that the strength of biopolymer stabilized soil columns degrades rapidly with moisture ingress (unpublished data). The authors demonstrated that the bond strength of the polymer degraded with moisture ingress. Nano-indentation allows us to measure the properties of biopolymer in both dry and hydrated conditions. Figure 7B compares the elastic moduli of a dry and a wet biopolymer subjected to a cycle of saturated wetting. The average modulus of the wet samples was $1.47 \mathrm{GPa}$, with a standard deviation of 0.057 . Thus, wetting was responsible for a reduction of modulus by more than $50 \%$. This study documents the powerful effect of hydration on biopolymer soil stabilizers. Water sorption partially plasticizes the polymers resulting in lowering their stiffness and elastic modulus (Hosaka et al., 2007). The disturbance of the biopolymer gel via hydrophilic water absorption leads to the biopolymer particles closer to the water breaking off from the main structure due to swelling. The detached particles have no interaction with the remaining structure leading to a loss in strength. The drying process leads to reattachment of the particles, but the original structure is not fully recovered, resulting in a loss of strength in each cycle. The penetration was performed in a matrix of $x-y$ positions. Figure 8 presents the results as colour contours. The 3 D image in Figure $\mathbf{8 B}$ shows the depth of a typical indent on the sample.

The modulus mapping results in Figure 9 a show that the elastic modulus of the biopolymer sample mainly varied between 2.9 and $3.8 \mathrm{GPa}$. The variation of modulus across the horizontal scan distance is shown in Figure 9B). The high standard deviation of the modulus at $\mathrm{X}=80 \mu \mathrm{m}$ and between $\mathrm{X}=120$ and $140 \mu \mathrm{m}$ (Figure 9B) may be due to the presence of surface defects or pores observed in the surface scanning. The elastic modulus of dried and well as hydrated biopolymer dextran has been reported for the first time in the paper. This 

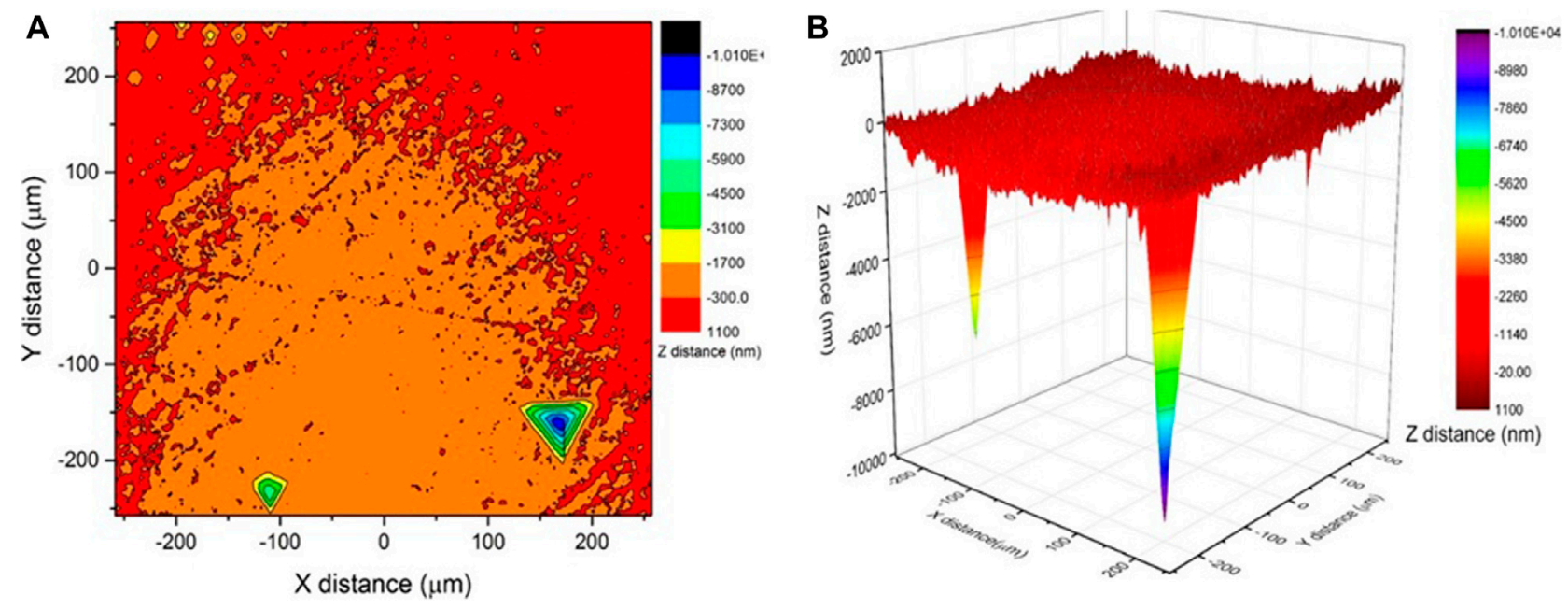

FIGURE 8 | Survey scanning results on the polished sample after indentation.
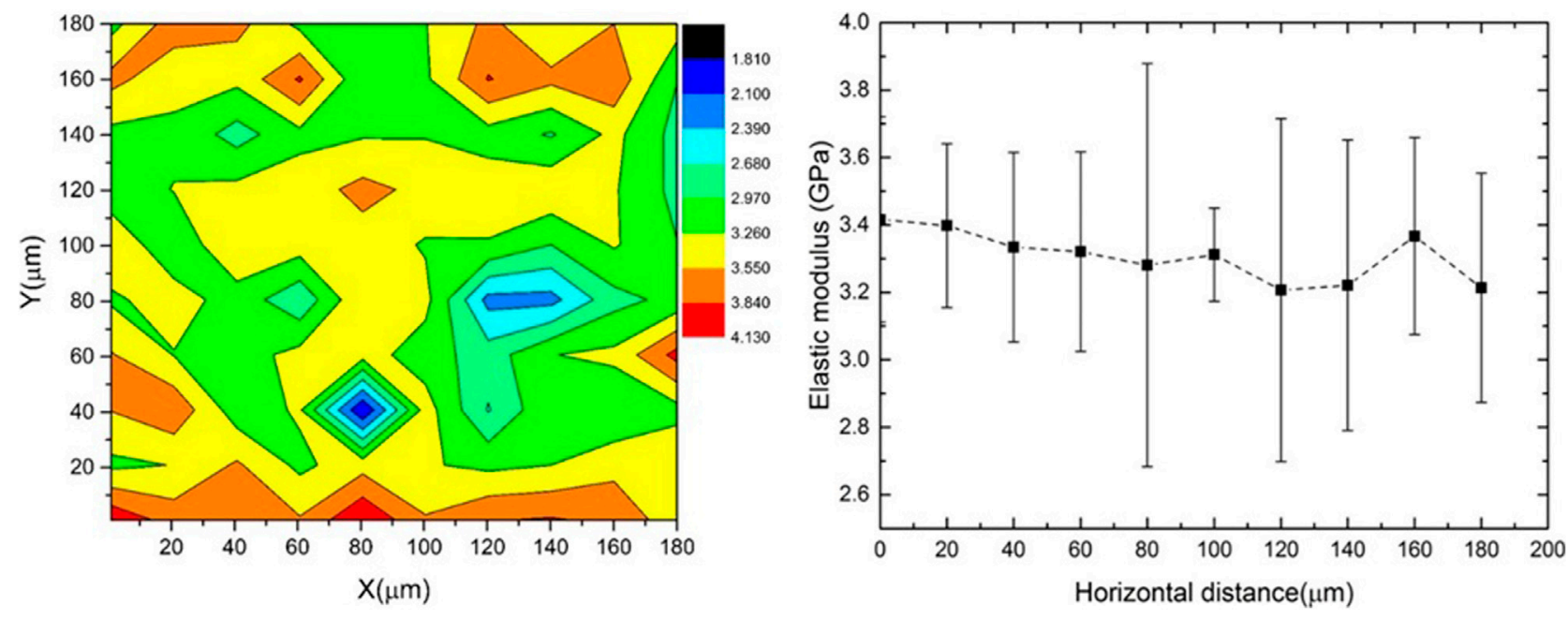

FIGURE 9 | (A) Modulus mapping on $180 \times 180$ micro $\mathrm{m}^{2}$ area using nanoindentation (B) variation in modulus across horizontal direction.

will be useful data for future modelling work on biopolymer stabilized soils.

\section{PeakForce QNM}

Figure 10 shows the comparison between surface scanning results obtained on $550 \times 500 \mu \mathrm{m}^{2}$ area using nanoindentation. The $256 \times 256$ pixel topography images of the scan area of size $20 \times 20 \mu^{2}$ of the biopolymer sample obtained through PeakForce QNM are shown in Figure 10. The image clearly shows the significant difference between resolutions of surface scanning images obtained using nanoindenter and AFM (Figure 10). The image reveals that even after polishing, the surface topography of the biopolymer sample has a wide variation. The dark areas in the image depict porous areas with low elastic modulus. The high standard deviation observed in the nanoindentation test at $\mathrm{X}=80 \mu \mathrm{m}$ might be due to the indent being placed on such an area which may not be visible due to the low resolution of the nanoindentation microscope objective. Even though the sample preparation should result in low roughness, the root means square roughness of the sample is $558 \mathrm{~nm}$. The surface profile of the in-situ biopolymer after drying is scanned using an AFM. Figure 10B reveals that the resolution of the AFM image is much higher than that of nanoindenter. The surface scanning results show the unevenness on the sample surface even after rigorous polishing. It helps to better understand the variation in nanomechanical properties of the sample. 

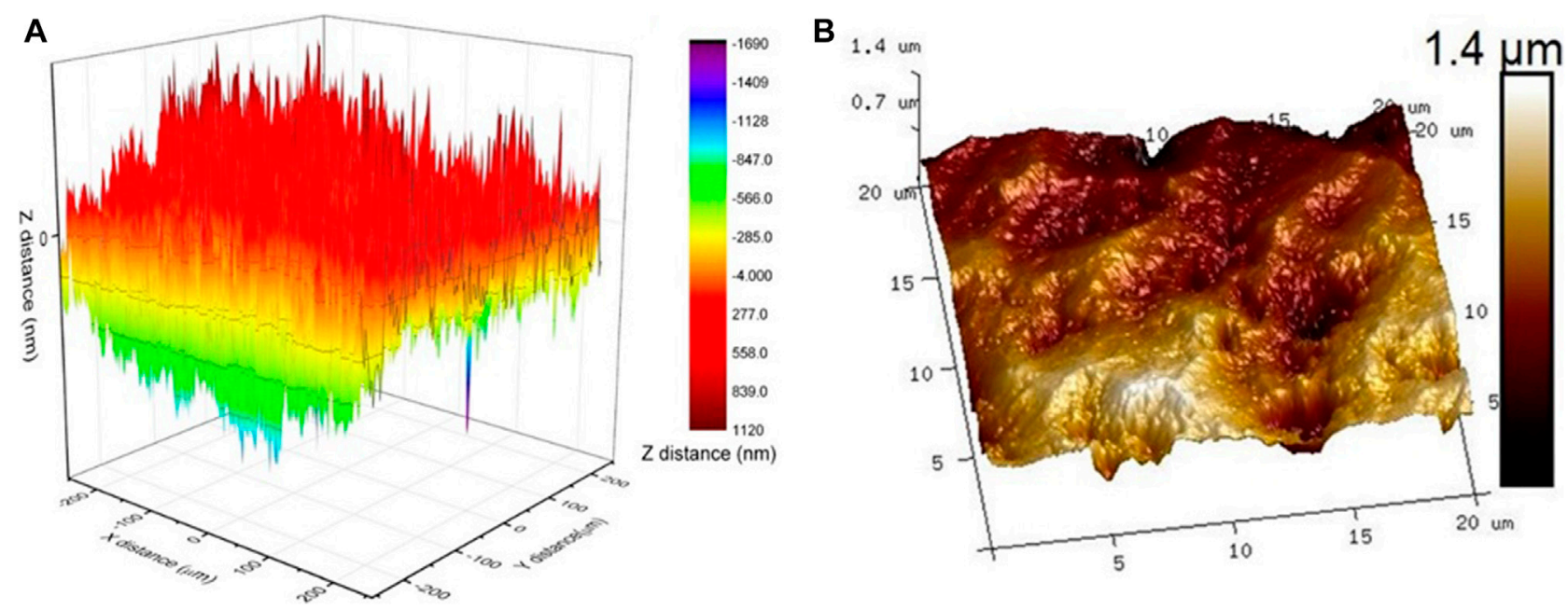

FIGURE 10 | Surface topography obtained from (A) nanoindentation $500 \times 500 \mu \mathrm{m}^{2}$ (B) PF-QNM on $20 \times 20 \mu \mathrm{m}^{2}$.
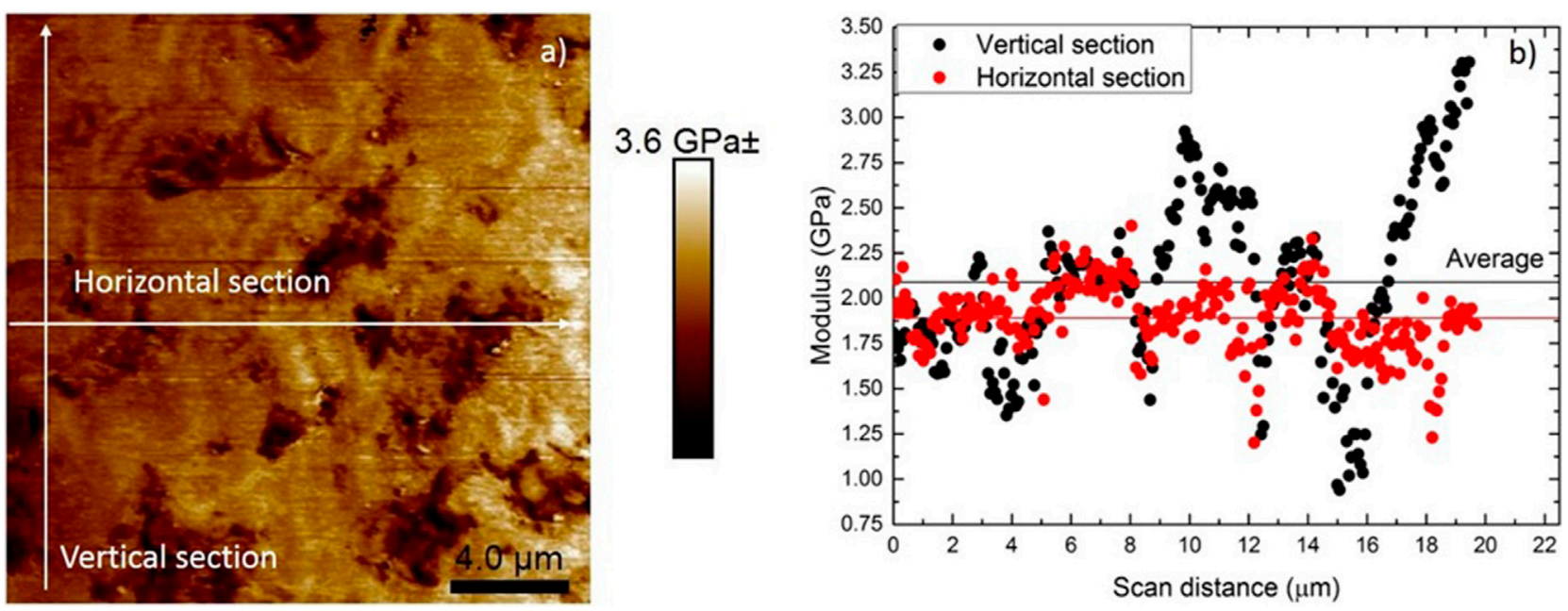

FIGURE 11 | (A) Modulus contour map and (B) modulus distribution across a horizontal and vertical section.

The modulus contour map in Figure 11A shows micro-level pores with low elastic modulus. Changes in elastic modulus were more prominent between the interface of the micropores and the sample. When pores or local depressions are encountered in the sample during scanning, the subsequent areas will display a lower modulus. In the modulus mapping image in Figure 11A, one can clearly see that the depressions have a lower modulus as compared to the other relatively smooth regions in the sample. The variation in modulus across a horizontal and vertical section can also be clearly seen in Figure 11B. The modulus obtained from PeakForce QNM was lower than that obtained from nanoindentation using CSM method. This is generally attributed to the confinement effect and plastic deformation in nanoindentation testing (Li et al., 2015). However, compared to nanoindentation PeakForce QNM allows for the evaluation of local mechanical properties within smaller measuring areas at the nanoscale. It can provide modulus maps with a higher spatial resolution which is very highly critical in a heterogeneous sample. Significantly lower elastic modulus is measured in areas with surface defects. Therefore, PeakForce QNM was successful in mapping the elastic modulus of the sample at higher resolutions as compared to nanoindentation, where indent spacing of $20 \mu \mathrm{m}$ was essential to avoid interference from subsequent indents. The average modulus across the vertical section was $2.09 \pm 0.48 \mathrm{GPa}$ and horizontal section $1.89 \pm 0.19 \mathrm{GPa}$. The reduction in modulus across the horizontals section is because the section passes through surface irregularities and pores, as clearly seen in Figure 11A.

\section{Needle Penetration}

The surface strength of in-situ bacterial biopolymer treated soils was tested by needle penetration. The stimulation of the bacteria Leuconostoc mesenteroids produced insoluble biopolymer 


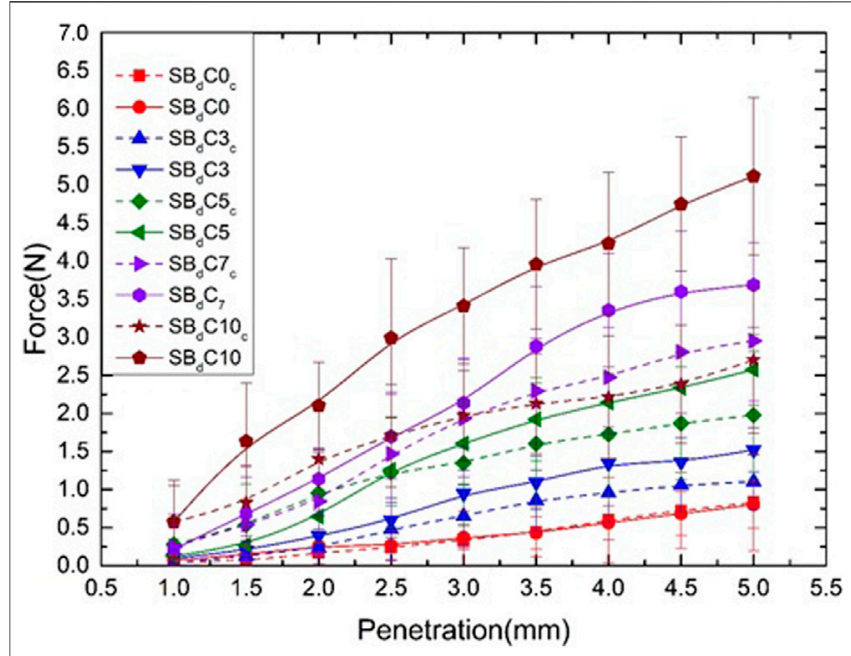

FIGURE 12 | Needle penetration of Petri-dish samples treated with insitu biopolymer.

within the soil matrix. Though it is a promising technology, the quantity of biopolymer produced is relatively small compared to the pore spaces in soil (Ham et al., 2018). Figure 12 shows the force-penetration graphs of samples treated with in-situ biopolymer. Firstly, the addition of in-situ biopolymer enhanced the surface strength of the treated samples. Further, the inclusion of clay enhanced the mechanical performance of the biopolymer treated sand. It can be observed that the needle penetration test can be used to predict approximate UCS values of the stabilized samples.

\section{Microscopic Investigation}

The SEM micrographs of uncoated samples after the needle penetration test are shown below (Figure 13). It is evident that the amount of in situ biopolymer produces is less to fill all the pore spaces in the soil matrix. However, we can notice that the in-situ polymer production is more in the grain contact areas as compared to the pores. This is due to the bacteria, who prefer to settle down in the grooves in the sand grains and secrete biopolymers thereafter. Similar results are seen from the study where bacteria are used to produce calcite to bridge the sand particles through the process of bio-mineralization. Hence, it is more advantageous to produce in-situ biopolymers than mixing it with soil are there is a more targeted production of the biopolymers in the former as compared to the latter. The SEM micrographs of biopolymer treated samples after the needle penetration test are shown in Figure 13. It is evident that the amount of in situ biopolymers produced is less to fill all the pore spaces in the soil matrix. However, it is observed that the in-situ polymer production is more targeted towards grain contact areas as compared to the pores as in Figure 13. This is due to the nature of the bacteria, which prefers to settle down in the grooves in the sand grains and secrete biopolymers/biominerals thereafter through their metabolic activities (Porter et al., 2017). Hence, it is more advantageous to produce in situ biopolymers than mixing them with soil since there is a more targeted production of the biopolymers in the former as compared to the latter. Figure 13 shows the formation of clay biopolymer matrix within the soil, which helps in filling the pores as well as creating grain contacts leading to higher penetration resistance.

\section{DISCUSSION}

\section{Bacterial Growth and Dextran Production}

The fundamental mechanism of bacterial biopolymer production was revealed using a model bacterium Leucononstoc mesenteroids. Exopolysaccharides produced from lactic acid bacteria (LAB) such as Leucononstoc mesenteroids is generally regarded as safe since they are widely used in the food industry (Aman et al., 2012). Among the several exopolysaccharides available today,
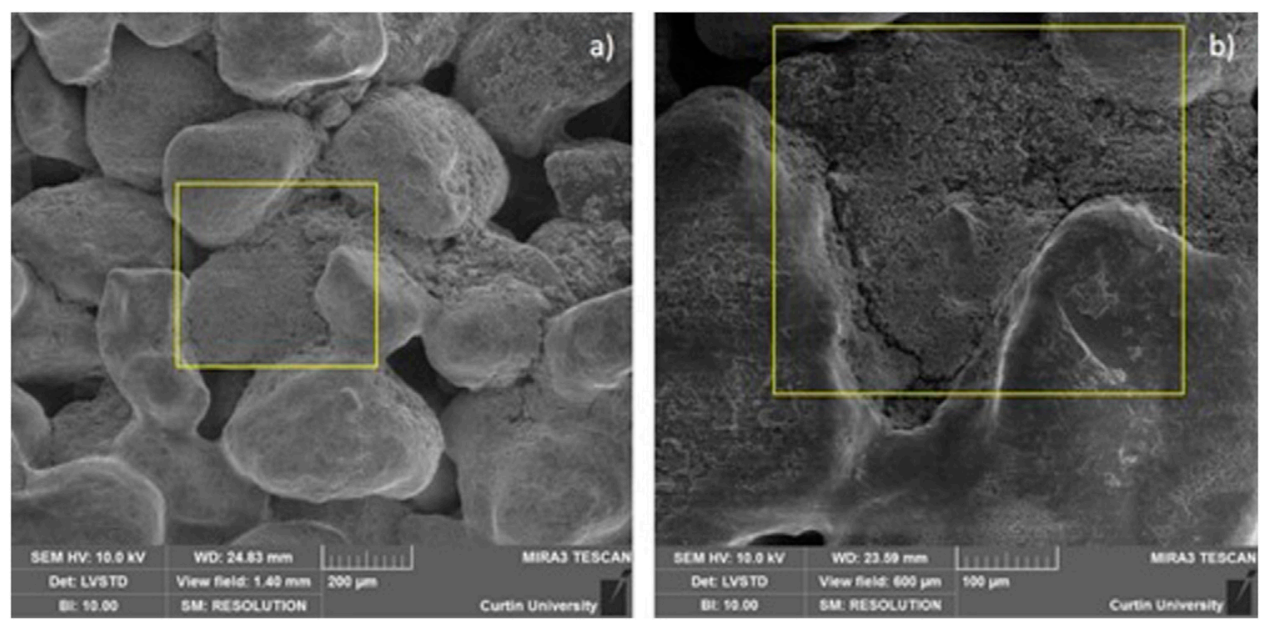

FIGURE 13 | SEM of in-situ biopolymer-clay matrix. 
dextran has gained recognition since Leucononstoc mesenteroids is capable of producing both soluble as well as insoluble dextran (Aman et al., 2012). Dextran is a homopolymer of glucose synthesized by dextransucrase in the presence of sucrose, and dextran produced by various strains differ in their type of branching, mass, glucosidic linkages, physical and chemical characteristics (Aman et al., 2012). Dextran is composed of $\alpha-1,6$ linkages (65\%) and combination of $\alpha-1,2$ linkages (27-30\%) and $\alpha-1,3$ linkages (Dols-Lafargue et al., 2001). The production of both dextransucrase and dextran is highly depended on various physicochemical factors. Sucrose concentration, neutral $\mathrm{pH}$ of 6.7 and high temperature $\left(40^{\circ} \mathrm{C}\right)$ were reported to be favourable for dextran production (DolsLafargue et al., 2001). Our study reports that at a maximum concentration of sucrose $(500 \mathrm{~g} / \mathrm{L})$, the dextran production was maximum (Figure 4). The data is consistent with literature which reports that dextran production increased with sucrose concentration up to 20\% (Santos et al., 2000; Kim et al., 2003). The reduction in $\mathrm{pH}$ with the production of dextran via fermentation, as seen in Figure $\mathbf{4}$ is also consistent with the literature (Siddiqui et al., 2014). The dextransucrase production is optimal at $\mathrm{pH}$ values between $7-8$, but the enzyme denatured irreversibly when maintained at that $\mathrm{pH}$ range for an extended period of time (Santos et al., 2000). The $\mathrm{pH}$ had much less effect on the molecular weight $s$ of the synthesized dextrans than the sucrose concentration or the temperature (Kim et al., 2003). The literature reports that the optimum conditions for the synthesis of very high molecular weight dextran are relatively low sucrose concentrations (0.1-0.3 M), high $\mathrm{pH}$ values of 5.5-6.0, and high temperature of $37-45^{\circ} \mathrm{C}$ (Kim et al., 2003). However, the optimum conditions for the synthesis of low molecular weight dextran would be high sucrose concentrations of 3.0-4.0 M, low $\mathrm{pH}$ (4.5), and intermediate temperatures of $23-28^{\circ} \mathrm{C}$ (Kim et al., 2003). It was observed that the dextran production was at higher sucrose concentration even though the OD was low (Figures 3, 4). This confirms that bound enzyme polymerizes the substrate sucrose to dextran without the need for additional cell growth (Santos et al., 2000).

\section{Nano and Micro-Mechanical Properties of Dextran}

Measuring the mechanical properties of biopolymers remains a challenge due to their multi-component nature and fragile structure (Pham et al., 2020). Investigation of mechanical properties of biopolymers and biopolymer stabilized soils is often limited to the macroscopic scale which does not provide information on interfacial properties and microstructure. In the present study, we employed a combination of atomic force microscopy (AFM) and instrumented nanoindentation to study the nanomechanical properties. Nanoindentation is a versatile technique reserved for the characterization of materials at the scale of heterogeneities or composite phases (Guessasma et al., 2008). However, Nanoindentation testing requires an adequate sample preparation because accurate results are obtained only if the depth of indentation is larger than the specimen's surface topography (Guessasma et al., 2008).
A meticulous preparation was carried out to significantly reduce the uncertainty in determining the surface properly before testing. The nanomechanical properties of bacterial dextran were unreported in literature hitherto. The modulus mapping results in Figure 9 a show that the elastic modulus of dextran mainly varied between 2.9 and $3.8 \mathrm{GPa}$. The average elastic modulus of the dry biopolymer is $3.14 \pm 0.035 \mathrm{GPa}$ at micro scale. The study also revealed that exposure to moisture was a major reason for the varying mechanical properties of the biopolymer.

AFM has been widely used to measure the nanomechanical properties of biological systems such as cell wall elasticity, cell surface polymers, and cell adhesion (Wang et al., 2015). Besides probing cell surface morphology and surface forces, AFM allows the characterization of the local mechanical properties of biological samples (Dorobantu and Gray 2010). In the present study, the average modulus across the vertical section was $2.09 \pm$ $0.48 \mathrm{GPa}$ and the horizontal section $1.89 \pm 0.19 \mathrm{GPa}$ at the nanoscale. The higher variation may be due to the presence of local irregularities on the sample surface due to polishing. Further, the study reports the presence of small nanoscale pores in dextran, which may also contribute to the variation in elastic modulus (Jeon et al., 2017). The radius of pores in dextran ranged from 1 to $100 \mu \mathrm{m}$, and $\sim 95 \%$ of the radius was less than $20 \mu \mathrm{m}$ (Jeon et al., 2017).

Previous studies reported that the biofilms formed under high nutrient conditions $(4.98 \pm 0.02 \mathrm{kPa})$ compared to that of biofilms formed under low nutrients of the biofilm of $C$. neoformans ranged from 0.1 to $6 \mathrm{GPa}$ (Pham et al., 2020). However, it is to be noted that the properties are measured under hydrated conditions (Allen et al., 2018). Moreover, the storage moduli of the biofilm of C. albicans varied from 0.1 to $4 \mathrm{GPa}$, while that conditions by Pseudomonas fluorescens were less stiff, as shown by their Young's modulus values $(2.35 \pm 0.08 \mathrm{kPa})$ (Allen et al., 2018). Unlike alginate biopolymers, the dextrans are neutrally charged. This means that even in the absence of any salt ions, attractive interactions will be present in dextran solutions leading to increased gelation (Padmanabhan et al., 2003). This makes dextran an ideal candidate for soil stabilization applications.

\section{Relationship Between Nano, Micro and Macro Mechanical Properties of the Biopolymer in Relation to Soil Stabilization}

Nanoindentation is a useful tool for an overall estimate of the stabilizer. PeakForce-QNM reveals the variation in properties at a smaller scale, enabling the study of microscopic changes in the stabilizer. Our previous study has revealed that the micro and nanomechanical properties of the stabilizer (biopolymer) directly affect the compressive strength of the stabilized samples at a macro-scale (Ramachandran et al., 2021). The needle penetration test is recommended by the International Society of Rock Mechanics (ISRM) for quick, non-destructive testing of the strength of the stabilized soils and soft rocks (Dubey et al., 2021). The ability to perform many tests without destroying the sample makes this method a better alternative to evaluate the stabilized soil than bulk strength properties such as 
Unconfined compressive strength (UCS) test. The needle penetration results are useful to understand the behaviour of the biopolymer stabilizer in the presence of soil (such as sand or clay). This information is difficult to achieve with nano and micro-scale measuring techniques since the sand particles are larger than the micron scale. The nanoindentation and AFM studies revealed the potential of dextran biopolymer as a standalone stabilizer, while the effect of dextran on soil was visualized by needle penetration testing. The tests revealed that the addition of dextran biopolymer enhanced the surface strength of the treated samples. Further, the inclusion of clay enhanced the mechanical performance of the biopolymer treated sand. This information is valuable when using biopolymer as a surface stabilizer.

\section{Implications on Soil Stabilization}

When Leucononstoc mesenteroids is grown within the soil, the accumulation of dextran can clog the pore spaces within the soil, leading to changes in soil properties. The effectiveness of biopolymers in aggregating soil relies on various factors. They include the amount of biopolymer production and survival of the bacteria in various soil conditions. It was observed that type of soil and sucrose concentration had a direct effect on the effectiveness of stabilization. The biopolymer stabilized samples had a higher surface strength when the soil has higher clay content (Figure 12). The scanning electron microscopy images of the tested sand revealed Dextran production within the pore spaces and coating the soil particles (Figure 13). The mechanism of stabilization includes increasing the cohesion of soils and reducing the void ratio. However, the quantity of dextran produced by the bacteria was quite low under in-situ conditions. Increasing the sucrose concentration and providing periodic injections can be used to overcome this limitation. Spraying method can be used for surface applications while injection method can be used for subsoil applications. The application of this technology includes permeability reduction in cohesionless soils. Other applications include reducing seepage through dams, biobarriers for contaminant remediation, prevention of soil liquefaction.

\section{Summary and Future Recommendations}

The use of bacterial biopolymers or biofilms has garnered significant interest as a promising means to cause bioclogging, reducing permeability, increasing strength, and eventually to seal cracks or leakage in various geotechnical engineering applications. With increasing focus on using bacterial biopolymers in geotechnical practices, quantification of mechanical properties of biopolymers is important in predicting their efficacy in soil stabilization applications. These micro and nanomechanical properties are quintessential in predicting the behaviour of biopolymer-modified soils. Yet, the till date these properties remain poorly identified. In the present study, biopolymer dextran produced by Leuconostoc mesenteroides was found to be a promising candidate in soil stabilization application. The model bacteria utilize sucrose as working material and synthesize biopolymer dextran, which forms a complex and inhomogeneous polymer network within the pore spaces of soil (Jeon et al., 2017). In the present study, the biopolymer yield was quantified, and its mechanical properties were measured at varying length scales. The study reports the first attempt to quantify the elastic modulus of dextran biopolymer using nanoindentation technique. Further, the elastic modulus was measured at higher resolution using AFM. Therefore, we demonstrate for the first time that the morphology and nanomechanical properties of dextran using various techniques such as nanoindentation, AFM and SEM. The obtained microscale properties are expected to be implemented for modelling of soil particle-soft biopolymer interactions at the particle scale.

Tailoring the morphology and material properties of biopolymers could confer new functionalities to sustainable stabilizers and would make possible novel advanced engineering applications. Achieving these targets would require the precipitation of stable biopolymers with tailored moduli and high hardness. The current study demonstrated that insoluble biopolymer dextran could be produced and used for soil stabilization applications. To the authors' knowledge, this is the first report of the direct measurement of the spatial variation in nanomechanical properties of dextran at various length scales. Further, in-situ dextran production was carried out on soil samples, and its efficacy was tested at macroscale using custom made needle penetration apparatus.

The conclusions are summarized as follows:

1. Successful optimization of biopolymer producing media and culture conditions was achieved in this study. We recorded linear increase in bacterial dextran production with the substrate concentration of sucrose between 15 and $500 \mathrm{~g} / \mathrm{L}$.

2. The micromechanical properties of in-situ biopolymer Dextran were quantified for the first time using nanoindentation technique. The average elastic modulus of the dry biopolymer is $3.14 \pm 0.035 \mathrm{GPa}$. The average hardness of the sample was $0.2 \mathrm{GPa}$.

3. The average modulus of the wet samples was $1.4 \pm 0.057 \mathrm{GPa}$. Hydration of the sample was responsible for a reduction of modulus by more than $50 \%$.

4. The average modulus of across the vertical section was $2.09 \pm$ $0.48 \mathrm{GPa}$ and horizontal section $1.89 \pm 0.19 \mathrm{GPa}$.

5. Needle penetration test results revealed that addition of in-situ biopolymer enhanced the surface strength of the treated samples. A needle penetration test can be used to predict approximate UCS values of the stabilized samples.

6. The variation in local micro and nanomechanical properties of dextran biopolymer produced in-situ by Leuconostoc mesenteroides was mapped for the first time using nanoindentation nd AFM techniques, respectively.

With increasing focus on using bacterial biopolymers in soil stabilization applications, quantification of mechanical properties of biopolymers become essential. However, to date, these properties remain poorly understood. This investigation is the first attempt to quantify the nano and macro mechanical properties of in-situ bacterial biopolymer 
dextran produced by bacterial culture Leucononstoc mesenteroids. The fundamental mechanism of bacterial biopolymer-based cementation was revealed through their morphographic and nanomechanical testing via AFM, nanoindentation and scanning electron micrography. Finally, its extended application on soil stabilization was investigated via needle penetration tests. Further, biopolymer dextran was found to be highly effective in stabilizing soils varying from sand to clay. This study has demonstrated novel methods for testing in situ polymers and opened up the channels for their applications in numerous subsurface as well as surface applications. However, the present work can be extended to include mechanical modelling of bacterial biopolymer stabilized soils. The Petridish samples should also be upscaled to carry out triaxial testing to obtain the cohesion and friction angle of the stabilized soils. A detailed geotechnical investigation of the stabilized soils will help in providing more confidence in biopolymer modified soil applications.

\section{KEY POINTS}

- Successful production and optimization of biopolymer dextran for soil stabilization applications were achieved.

- The micromechanical properties of in-situ biopolymer dextran were quantified for the first time using advanced characterization techniques.

\section{REFERENCES}

Abbasi, B., Ta, H. X., Muhunthan, B., Ramezanian, S., Abu-Lail, N., and Kwon, T.H. (2018). Modeling of Permeability Reduction in Bioclogged Porous Sediments. J. Geotech. Geoenviron. Eng. 144 (4), 04018016. doi:10.1061/ (asce)gt.1943-5606.0001869

Allen, A., Habimana, O., and Casey, E. (2018). The Effects of Extrinsic Factors on the Structural and Mechanical Properties of Pseudomonas Fluorescens Biofilms: A Combined Study of Nutrient Concentrations and Shear Conditions. Colloids Surf. B: Biointerfaces 165, 127-134. doi:10.1016/ j.colsurfb.2018.02.035

Aman, A., Siddiqui, N. N., and Qader, S. A. U. (2012). Characterization and Potential Applications of High Molecular Weight Dextran Produced by Leuconostoc Mesenteroides AA1. Carbohydr. Polym. 87 (1), 910-915. doi:10.1016/j.carbpol.2011.08.094

Arab, M. G., Mousa, R. A., Gabr, A. R., Azam, A. M., El-Badawy, S. M., and Hassan, A. F. (2019). Resilient Behavior of Sodium Alginate-Treated Cohesive Soils for Pavement Applications. J. Mater. Civ. Eng. 31 (1), 04018361. doi:10.1061/(asce) mt.1943-5533.0002565

Ayeldeen, M., Negm, A., El-Sawwaf, M., and Kitazume, M. (2017). Enhancing Mechanical Behaviors of Collapsible Soil Using Two Biopolymers. J. Rock Mech. Geotechnical Eng. 9 (2), 329-339. doi:10.1016/j.jrmge.2016.11.007

Bouazza, A., Gates, W. P., and Ranjith, P. G. (2009). Hydraulic Conductivity of Biopolymer-Treated Silty Sand. Géotechnique 59 (1), 71-72. doi:10.1680/ geot.2007.00137

Cabalar, A. F., Wiszniewski, M., and Skutnik, Z. (2017). Effects of Xanthan Gum Biopolymer on the Permeability, Odometer, Unconfined Compressive and Triaxial Shear Behavior of a Sand. Soil Mech. Found. Eng. 54 (5), 356-361. doi:10.1007/s11204-017-9481-1
- Atomic Force Microscopy (AFM) and nanoindentation techniques were used to probe the mechanical properties of dextran biopolymer at nanoscale and microscale, respectively.

- Multiscale mechanical testing is crucial to understanding the suitability of a biopolymer in soil stabilization applications.

\section{DATA AVAILABILITY STATEMENT}

The raw data supporting the conclusions of this article will be made available by the authors, without undue reservation.

\section{AUTHOR CONTRIBUTIONS}

AR performed the experiments, analysis of data and writing. ND contributed to the data analysis and supervision. AM contributed to the analysis of data and supervision. All authors read and approved the final manuscript.

\section{FUNDING}

The funding for this study was provided by Curtin University, Western Australia, Australia (CIPRS Scholarship).

Callebaut, F., Gabriels, D., Minjauw, W., and de Boodt, M. (1985). Determination of Soil Surface Strength with a Needle-type Penetrometer. Soil Tillage Res. 5 (3), 227-245. doi:10.1016/0167-1987(85)90017-0

Cedrati, V., Pacini, A., Nitti, A., Martínez de Ilarduya, A., Muñoz-Guerra, S., Sanyal, A., et al. (2020). "Clickable” Bacterial Poly( $\gamma$-Glutamic Acid). Polym. Chem. 11 (35), 5582-5589. doi:10.1039/d0py00843e

Chang, I., Lee, M., Tran, A. T. P., Lee, S., Kwon, Y.-M., Im, J., et al. (2020). Review on Biopolymer-Based Soil Treatment (BPST) Technology in Geotechnical Engineering Practices. Transportation Geotechnics 24, 100385. doi:10.1016/ j.trgeo.2020.100385

Chen, R., Ding, X., Lai, H., and Zhang, L. (2021). Improving Dust Resistance of Mine Tailings Using green Biopolymer. Environ. Geotechnics 8 (6), 382-391. doi:10.1680/jenge.18.00089

Chen, R., Lee, I., and Zhang, L. (2015). Biopolymer Stabilization of Mine Tailings for Dust Control. J. Geotech. Geoenviron. Eng. 141 (2), 04014100. doi:10.1061/ (asce)gt.1943-5606.0001240

Choi, S.-G., Chang, I., Lee, M., Lee, J.-H., Han, J.-T., and Kwon, T.-H. (2020). Review on Geotechnical Engineering Properties of Sands Treated by Microbially Induced Calcium Carbonate Precipitation (MICP) and Biopolymers. Construction Building Mater. 246, 118415. doi:10.1016/ j.conbuildmat.2020.118415

Cole, D. M., Ringelberg, D. B., and Reynolds, C. M. (2012). Small-scale Mechanical Properties of Biopolymers. J. Geotech. Geoenviron. Eng. 138 (9), 1063-1074. doi:10.1061/(asce)gt.1943-5606.0000680

Couradeau, E., Benzerara, K., Moreira, D., Gérard, E., Kaźmierczak, J., Tavera, R., et al. (2011). Prokaryotic and Eukaryotic Community Structure in Field and Cultured Microbialites from the Alkaline Lake Alchichica (Mexico). PloS One 6 (12), e28767. doi:10.1371/journal.pone.0028767

Dehghan, H., Tabarsa, A., Latifi, N., and Bagheri, Y. (2019). Use of Xanthan and Guar Gums in Soil Strengthening. Clean. Techn Environ. Pol. 21 (1), 155-165. doi:10.1007/s10098-018-1625-0 
DeJong, J., Soga, K., Kavazanjian, E., Burns, S., Van Paassen, L., Al Qabany, A., et al. (2014). Biogeochemical Processes and Geotechnical Applications: Progress, Opportunities and Challenges. Bio-And Chemo-Mechanical Processes in Geotechnical Engineering: Géotechnique Symposium in Print 2013. London: Ice Publishing.

Dhami, N. K., Mukherjee, A., and Watkin, E. L. J. (2018). Microbial Diversity and Mineralogical-Mechanical Properties of Calcitic Cave Speleothems in Natural and In Vitro Biomineralization Conditions. Front. Microbiol. 9, 40. doi:10.3389/ fmicb.2018.00040

Dhami, N. K., Reddy, M. S., and Mukherjee, A. (2013). Biomineralization of Calcium Carbonate Polymorphs by the Bacterial Strains Isolated from Calcareous Sites. J. Microbiol. Biotechnol. 23 (5), 707-714. doi:10.4014/ jmb.1212.11087

Dols-Lafargue, M., Willemot, R.-M., Monsan, P. F., and Remaud-Simeon, M. (2001). Factors Affecting ?,-1,2 Glucooligosaccharide Synthesis byLeuconostoc Mesenteroides NRRL B-1299 Dextransucrase. Biotechnol. Bioeng. 74 (6), 498-504. doi:10.1002/bit.1141

Dorobantu, L. S., and Gray, M. R. (2010). Application of Atomic Force Microscopy in Bacterial Research. Scanning 32 (2), 74-96. doi:10.1002/sca.20177

Dubey, A. A., Ravi, K., Mukherjee, A., Sahoo, L., Abiala, M. A., and Dhami, N. K. (2021). Biocementation Mediated by Native Microbes from Brahmaputra riverbank for Mitigation of Soil Erodibility. Scientific Rep. 11 (1), 1-15. doi:10.1038/s41598-021-94614-6

Fatehi, H., Abtahi, S. M., Hashemolhosseini, H., and Hejazi, S. M. (2018). A Novel Study on Using Protein Based Biopolymers in Soil Strengthening. Construction Building Mater. 167, 813-821. doi:10.1016/j.conbuildmat.2018.02.028

Godinho, A. L., and Bhosle, S. (2009). Sand Aggregation by ExopolysaccharideProducing Microbacterium Arborescens-AGSB. Curr. Microbiol. 58 (6), 616-621. doi:10.1007/s00284-009-9400-4

Gowthaman, S., Iki, T., Nakashima, K., Ebina, K., and Kawasaki, S. (2019). Feasibility Study for Slope Soil Stabilization by Microbial Induced Carbonate Precipitation (MICP) Using Indigenous Bacteria Isolated from Cold Subarctic Region. SN Appl. Sci. 1 (11), 1480. doi:10.1007/s42452-019-1508-y

Guessasma, S., Sehaki, M., Lourdin, D., and Bourmaud, A. (2008). Viscoelasticity Properties of Biopolymer Composite Materials Determined Using Finite Element Calculation and Nanoindentation. Comput. Mater. Sci. 44 (2), 371-377. doi:10.1016/j.commatsci.2008.03.038

Ham, S.-M., Chang, I., Noh, D.-H., Kwon, T.-H., and Muhunthan, B. (2018). Improvement of Surface Erosion Resistance of Sand by Microbial Biopolymer Formation. J. Geotech. Geoenviron. Eng. 144 (7), 06018004. doi:10.1061/(asce) gt.1943-5606.0001900

Hosaka, K., Tagami, J., Nishitani, Y., Yoshiyama, M., Carrilho, M., Tay, F. R., et al. (2007). Effect of Wet vs. Dry Testing on the Mechanical Properties of Hydrophilic Self-Etching Primer Polymers. Eur. J. Oral Sci. 115 (3), 239-245. doi:10.1111/j.1600-0722.2007.00452.x

Jee, A.-Y., and Lee, M. (2010). Comparative Analysis on the Nanoindentation of Polymers Using Atomic Force Microscopy. Polym. Test. 29 (1), 95-99. doi:10.1016/j.polymertesting.2009.09.009

Jeon, M.-K., Kwon, T.-H., Park, J.-S., and Shin, J. H. (2017). In Situ viscoelastic Properties of Insoluble and Porous Polysaccharide Biopolymer Dextran Produced by Leuconostoc Mesenteroides Using Particle-Tracking Microrheology. Geomech. Eng. 12 (5), 849-862. doi:10.12989/ gae.2017.12.5.849

Jeong, M. S., Noh, D.-H., Hong, E., Lee, K. S., and Kwon, T.-H. (2019). Systematic Modeling Approach to Selective Plugging UsingIn SituBacterial Biopolymer Production and its Potential for Microbial-Enhanced Oil Recovery. Geomicrobiology J. 36 (5), 468-481. doi:10.1080/ 01490451.2019.1573277

Jung, J. Y., Lee, S. H., Lee, H. J., Seo, H.-Y., Park, W.-S., and Jeon, C. O. (2012). Effects of Leuconostoc Mesenteroides Starter Cultures on Microbial Communities and Metabolites during Kimchi Fermentation. Int. J. Food Microbiol. 153 (3), 378-387. doi:10.1016/j.ijfoodmicro.2011.11.030

Kim, D., Robyt, J. F., Lee, S.-Y., Lee, J.-H., and Kim, Y.-M. (2003). Dextran Molecular Size and Degree of Branching as a Function of Sucrose Concentration, $\mathrm{pH}$, and Temperature of Reaction of Leuconostoc Mesenteroides B-512FMCM Dextransucrase. Carbohydr. Res. 338 (11), 1183-1189. doi:10.1016/s0008-6215(03)00148-4
Kim, Y.-M., Park, T., and Kwon, T.-H. (2019). Engineered Bioclogging in Coarse Sands by Using Fermentation-Based Bacterial Biopolymer Formation. Geomech. Engng 17, 485-496. doi:10.12989/gae.2019.17.5.485

Lee, S., Chung, M., Park, H. M., Song, K.-I., and Chang, I. (2019). Xanthan Gum Biopolymer as Soil-Stabilization Binder for Road Construction Using Local Soil in Sri Lanka. J. Mater. Civ. Eng. 31 (11), 06019012. doi:10.1061/(asce)mt.19435533.0002909

Li, C., Ostadhassan, M., Kong, L., and Bubach, B. (2019). Multi-scale Assessment of Mechanical Properties of Organic-Rich Shales: A Coupled Nanoindentation, Deconvolution Analysis, and Homogenization Method. J. Pet. Sci. Eng. 174, 80-91. doi:10.1016/j.petrol.2018.10.106

Li, W., Xiao, J., Kawashima, S., Shekhawat, G. S., and Shah, S. P. (2015). Experimental Investigation on Quantitative Nanomechanical Properties of Cement Paste. Aci Mater. J. 112 (2), 6986. doi:10.14359/51686986

Martin, G., Yen, T., and Karimi, S. (1996). Application of Biopolymer Technology in Silty Soil Matrices to Form Impervious Barriers 7th Australia New Zealand Conference on Geomechanics: Geomechanics in a Changing World: Conference Proceedings. Australia: Institution of Engineers.

Nix, W. D., and Gao, H. (1998). Indentation Size Effects in Crystalline Materials: A Law for Strain Gradient Plasticity. J. Mech. Phys. Sol. 46 (3), 411-425. doi:10.1016/s0022-5096(97)00086-0

Noh, D.-H., Ajo-Franklin, J. B., Kwon, T.-H., and Muhunthan, B. (2016). PandSwave Responses of Bacterial Biopolymer Formation in Unconsolidated Porous media. J. Geophys. Res. Biogeosci. 121 (4), 1158-1177. doi:10.1002/ 2015jg003118

Oliver, W. C., and Pharr, G. M. (1992). An Improved Technique for Determining Hardness and Elastic Modulus Using Load and Displacement Sensing Indentation Experiments. J. Mater. Res. 7 (6), 1564-1583. doi:10.1557/ jmr.1992.1564

Padmanabhan, P. A., Kim, D.-S., Pak, D., and Sim, S. J. (2003). Rheology and Gelation of Water-Insoluble Dextran from Leuconostoc Mesenteroides NRRL B-523. Carbohydr. Polym. 53 (4), 459-468. doi:10.1016/s01448617(03)00140-1

Pham, D. Q., Bryant, S. J., Cheeseman, S., Huang, L. Z. Y., Bryant, G., Dupont, M. F., et al. (2020). Micro- to Nano-Scale Chemical and Mechanical Mapping of Antimicrobial-Resistant Fungal Biofilms. Nanoscale 12 (38), 19888-19904. doi:10.1039/d0nr05617k

Porter, H., Dhami, N. K., and Mukherjee, A. (2017). Synergistic Chemical and Microbial Cementation for Stabilization of Aggregates. Cement and Concrete Composites 83, 160-170. doi:10.1016/j.cemconcomp.2017.07.015

Proto, C. J., DeJong, J. T., and Nelson, D. C. (2016). Biomediated Permeability Reduction of Saturated Sands. J. Geotech. Geoenviron. Eng. 142 (12), 04016073. doi:10.1061/(asce)gt.1943-5606.0001558

Puppi, D., Migone, C., Morelli, A., Bartoli, C., Gazzarri, M., Pasini, D., et al. (2016). Microstructured Chitosan/poly( $\gamma$-Glutamic Acid) Polyelectrolyte Complex Hydrogels by Computer-Aided Wet-Spinning for Biomedical ThreeDimensional Scaffolds. J. Bioactive Compatible Polym. 31 (5), 531-549. doi:10.1177/0883911516631355

Ramachandran, A. L., Dubey, A. A., Dhami, N. K., and Mukherjee, A. (2021). Multiscale Study of Soil Stabilization Using Bacterial Biopolymers. J. Geotech. Geoenviron. Eng. 147 (8), 04021074. doi:10.1061/(asce)gt.1943-5606.0002575

Ramachandran, A. L., Polat, P., Mukherjee, A., and Dhami, N. K. (2020). Understanding and Creating Biocementing Beachrocks via Biostimulation of Indigenous Microbial Communities. Appl. Microbiol. Biotechnol. 104 (8), 3655-3673. doi:10.1007/s00253-020-10474-6

Ringelberg, D. B., Cole, D. M., Foley, K. L., Ruidaz-Santiago, C. M., and Reynolds, C. M. (2014). Compressive Strength of Soils Amended with a Bacterial Succinoglycan: Effects of Soluble Salts and Organic Matter. Can. Geotech. J. 51 (7), 747-757. doi:10.1139/cgj-2012-0369

Santos, M., Teixeira, J., and Rodrigues, A. (2000). Production of Dextransucrase, Dextran and Fructose from Sucrose Using Leuconostoc Mesenteroides NRRL B512(f). Biochem. Eng. J. 4 (3), 177-188. doi:10.1016/s1369-703x(99)00047-9

Sarwat, F., Qader, S. A. U., Aman, A., and Ahmed, N. (2008). Production \& Characterization of a Unique Dextran from an Indigenous Leuconostoc Mesenteroides CMG713. Int. J. Biol. Sci. 4 (6), 379-386. doi:10.7150/ijbs.4.379 Siddiqui, N. N., Aman, A., Silipo, A., Qader, S. A. U., and Molinaro, A. (2014). Structural Analysis and Characterization of Dextran Produced by Wild and 
Mutant Strains of Leuconostoc Mesenteroides. Carbohydr. Polym. 99, 331-338. doi:10.1016/j.carbpol.2013.08.004

Smolyakov, G., Pruvost, S., Cardoso, L., Alonso, B., Belamie, E., and DuchetRumeau, J. (2016). AFM PeakForce QNM Mode: Evidencing Nanometre-Scale Mechanical Properties of Chitin-Silica Hybrid Nanocomposites. Carbohydr. Polym. 151, 373-380. doi:10.1016/j.carbpol.2016.05.042

Ta, H. X., Muhunthan, B., Ramezanian, S., Abu-Lail, N., and Kwon, T.-H. (2017). Effects of Bacterial Dextran on Soil Geophysical Properties. Environ. Geotech. 5 (2), 114-122. doi:10.1680/jenge.15.00059

Terzis, D., and Laloui, L. (2019). A Decade of Progress and Turning Points in the Understanding of Bio-Improved Soils: A Review. Geomechanics Energ. Environ. 19, 100116. doi:10.1016/j.gete.2019.03.001

Ulusay, R., Aydan, Ö., Erguler, Z. A., Ngan-Tillard, D. J. M., Seiki, T., Verwaal, W., et al. (2014). ISRM Suggested Method for the Needle Penetration Test. Rock Mech. Rock Eng. 47 (3), 1073-1085. doi:10.1007/s00603-013-0534-0

Wang, H., Wilksch, J. J., Strugnell, R. A., and Gee, M. L. (2015). Role of Capsular Polysaccharides in Biofilm Formation: An AFM Nanomechanics Study. ACS Appl. Mater. Inter. 7 (23), 13007-13013. doi:10.1021/acsami.5b03041

Wang, S. F., Shen, L., Tong, Y. J., Chen, L., Phang, I. Y., Lim, P. Q., et al. (2005). Biopolymer Chitosan/montmorillonite Nanocomposites: Preparation and Characterization. Polym. Degrad. Stab. 90 (1), 123-131. doi:10.1016/j.polymdegradstab.2005.03.001
Zhu, W., Hughes, J. J., Bicanic, N., and Pearce, C. J. (2007). Nanoindentation Mapping of Mechanical Properties of Cement Paste and Natural Rocks. Mater. Charact. 58 (11-12), 1189-1198. doi:10.1016/j.matchar.2007.05.018

Conflict of Interest: The authors declare that the research was conducted in the absence of any commercial or financial relationships that could be construed as a potential conflict of interest.

Publisher's Note: All claims expressed in this article are solely those of the authors and do not necessarily represent those of their affiliated organizations, or those of the publisher, the editors and the reviewers. Any product that may be evaluated in this article, or claim that may be made by its manufacturer, is not guaranteed or endorsed by the publisher.

Copyright $\odot 2022$ Ramachandran, Mukherjee and Dhami. This is an open-access article distributed under the terms of the Creative Commons Attribution License (CC $B Y$ ). The use, distribution or reproduction in other forums is permitted, provided the original author(s) and the copyright owner(s) are credited and that the original publication in this journal is cited, in accordance with accepted academic practice. No use, distribution or reproduction is permitted which does not comply with these terms. 